\title{
Gastric emptying in control subjects and patients with duodenal ulcer before and after vagotomy
}

\author{
P. J. HOWLETT, H. J. SHEINER, D. C. BARBER, A. S. WARD, \\ C. A. PEREZ-AVILA, AND H. L. DUTHIE \\ From the Departments of Surgery and Medical Physics, Sheffield Royal Informary, Sheffield
}

SUMMARY The emptying of a solid meal labelled with Indium ${ }^{113 m D T P A}$ from the stomach was studied with a gamma camera in 26 normal subjects, 27 patients with duodenal ulcer, on 41 occasions after truncal vagotomy and pyloroplasty and 38 times after highly selective vagotomy. Applying the method of principal component analysis to the results, differences were detected between control and duodenal ulcer subjects and two probable subgroups of duodenal ulcer were observed. Half emptying times did not reveal these patterns. After vagotomy, delayed emptying was general at one week. At one month, patients after highly selective vagotomy had a more normal result than those with truncal vagotomy and pyloroplasty (TV), but by six months no significant difference in overall emptying rate was found, although changes in the pattern of gastric emptying persisted in some patients after TV.

The unpleasant sequelae of diarrhoea and dumping which sometimes complicate vagotomy and pyloroplasty (TV) have been attributed to rapid gastric emptying (McKelvey, 1970; Humphrey et al., 1972; Clarke and Alexander-Williams, 1973). In order to avoid these disturbances, the operation of highly selective vagotomy (HSV) has been advocated (Johnston and Wilkinson, 1970). Experimental evidence showed that antral motility was less disturbed after HSV than after TV (Kelly and Kennedy, 1971; Wilbur and Kelly, 1973) and clinical trials suggested that the incidence of dumping and diarrhoea was also less in patients after HSV (Amdrup et al., 1974). However, the evidence for a more controlled rate and pattern of gastric emptying with HSV was less convincing. When liquid meals were used, the rate of emptying after HSV was still more rapid than normal (Moberg et al., 1972; Clarke and Alexander-Williams, 1973). With 'nutritional' contrast meals the rate of emptying was said to be normal (Pederson and Amdrup, 1970; Madsen et al., 1973), but this method was capable of measuring only total emptying times and was therefore relatively crude compared with other techniques.

With solid meals some preliminary reports are available. In one (Alexander-Williams et al., 1973) gastric emptying was found to be normal after HSV.

Received for publication 29 March 1976
In another (Howlett et al., 1974) there was delayed emptying soon after surgery in patients who had either TV or HSV. However, the rate soon returned to normal after HSV and this trend was also evident in over half the TV patients.

This paper expands on our preliminary report on emptying of a solid meal and compares symptoms with emptying rates.

\section{Method}

The meal consisted of meat, peas, and mashed potatoes, the total weight being $250 \mathrm{~g}$. Indium 113mDPTA (diethylene triamine pentaacetic acid) was incorporated in the potatoes (Howlett et al., 1974). The activity over the stomach was measured using a gamma camera. Radioactivity in the intestine was excluded from counting by defining the lower edge of the greater curvature of the stomach electronically. Photographs of the full area of the gamma camera screen were obtained for comparison, and confirmed that the defining of the greater curvature mentioned above satisfactorily separated the gastric and small bowel areas. The study period from the time of starting to eat continued for 60 minutes. Data were collected in one minute counts and stored on a computer disc for subsequent analysis. This technique gave a reproducible result to within $10 \%$ both in relation to half emptying time and principal com- 
Table 1 Patients having tests of gastric emptying

\begin{tabular}{|c|c|c|c|c|c|c|}
\hline \multirow[t]{2}{*}{ Group } & \multirow[t]{2}{*}{ Preop. } & \multicolumn{3}{|c|}{ Time after operation } & \multirow{2}{*}{$\begin{array}{l}\text { Four completed } \\
\text { sequential studies }\end{array}$} & \multirow{2}{*}{$\begin{array}{l}\text { Clinical assessment } \\
\text { at six months }\end{array}$} \\
\hline & & 1 week & 1 month & 6 months & & \\
\hline HSV & 14 & 14 & 10 & 14 & 7 & 12 \\
\hline TV & 13 & 14 & 13 & 14 & 7 & 12 \\
\hline
\end{tabular}

HSV: Highly selective vagotomy.

TV: Truncal vagotomy and pyloroplasty.

ponent analysis on the basis of two studies performed on each of eight subjects (Barber et al., 1974).

The setting up of the electronic device to define the gastric area took from five to 10 minutes and five to 15 minutes were needed for eating the meal. Data collected between 25 and 60 minutes were submitted to component analysis. However, photographic records were available from finishing the meal and radioisotopic counts from almost all tests before 25 minutes. No precipitate early emptying was observed.

A total of 132 studies were done-26 on normal volunteers and 27 on patients with uncomplicated duodenal ulcers subsequently proven at operation. After vagotomy 79 further tests were performed -41 after truncal vagotomy and pyloroplasty (TV) and 38 after highly selective vagotomy (HSV) (Table 1). The age ranged between 20 and 60 years. A pentagastrin test $(6 \mu \mathrm{g} / \mathrm{kg}$ intramuscularly) of acid gastric secretion was made in 15 of 27 patients with duodenal ulceration. Postprandial symptoms were assessed in 24 patients six months after operation by an independent observer.

Three methods of analysis of the gastric emptying curve were used:

\section{PRINCIPAL COMPONENT ANALYSIS}

In this computer-based analysis (Barber et al., 1974), all the data from the 132 emptying curves were pooled and for each patient three numbers or coefficients were derived which typified three features of the emptying pattern. In outline, the process was as follows-a mean curve was made from all the data so that all types of curve were included and so that any particular feature, such as fast initial emptying, would be detectable. The mean curve was subtracted from each individual curve and these differences were combined to give the first component. The extent to which this component was present in an individual curve was called the first coefficient. The process was repeated to give the second and third coefficients. The first coefficient was indicative of the overall rate of emptying as shown by its relationship with the half emptying time (Fig. 1). The second coefficient was related to the pattern of emptying over the last two-thirds of the curve. When it was convex upwards at this time the curve had a positive second coefficient. It was negative when concave upwards (Fig. 2a). The third coefficient referred to the first third of the emptying curve. When rapid emptying took place at this time the curve was concave upwards and the third coefficient was positive. A negative third coefficient indicated a slower intial emptying - that is, the curve was convex upwards (Fig. 3).

\section{HALF EMPTYING TIME}

With the use of a computer, the best fit to a semilogarithmic plot of the data was obtained for the common time interval of 25 to 60 minutes. The conventional half emptying time ( $\left.\mathrm{T} \frac{1}{2}\right)$ was computed from this fit.

\section{EARLY EMPTYING PHASE}

Counts were available before 25 minutes in almost all studies. To assess whether the emptying in this period was different from that after 25 minutes a ratio was formed. The change in counts measured from the beginning of recording to the 25 minute point-for example, over the immediately preceding 10 minutes-was compared with the change in counts measured for the immediately succeeding identical interval beginning at the 25 minute pointthat is, 10 minutes in the example. The latter count was used as the denominator of the ratio. When the ratio was unity, gastric emptying proceeded at an even rate. A ratio of less than unity indicated more rapid emptying in the period before 25 minutes. Conversely, a ratio of more than unity indicated a slower rate of emptying in the early phase.

\section{Results}

\section{CONTROLS AND PATIENTS BEFORE VAGOTOMY}

Principal component analysis The first coefficient showed no difference between groups. The second coefficient had a bimodal distribution in the duodenal ulcer group (Fig. 4). Although the means of normal and duodenal ulcer groups were not statistically different, a comparison of their distributions showed a significant difference $(P<0.01)$. The duo- 


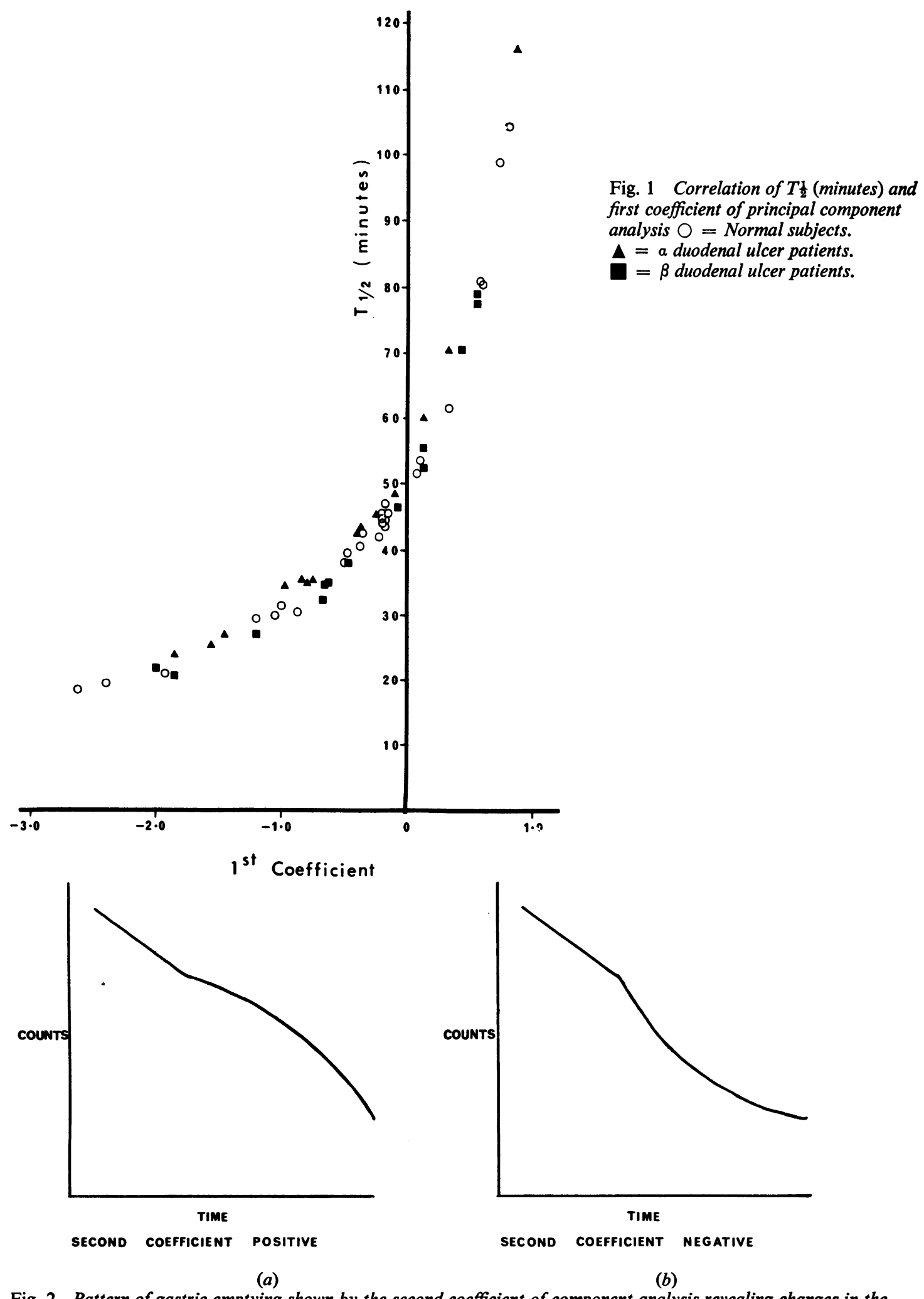

Fig. 2 Pattern of gastric emptying shown by the second coefficient of component analysis revealing changes in the latter part of the emptying curve. 


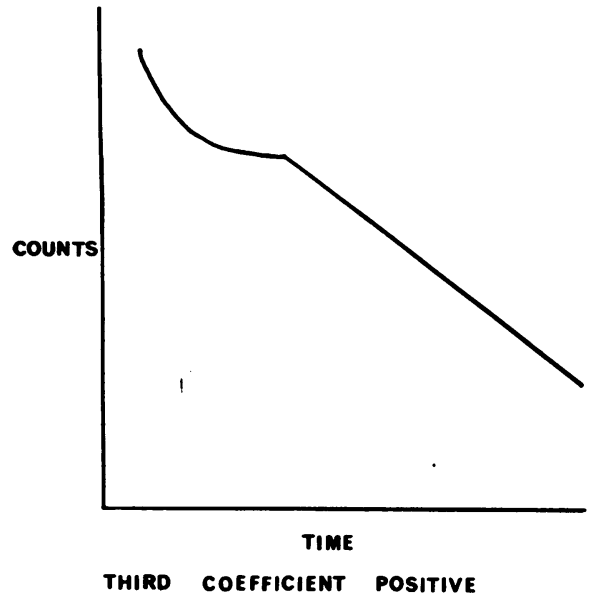

(a)

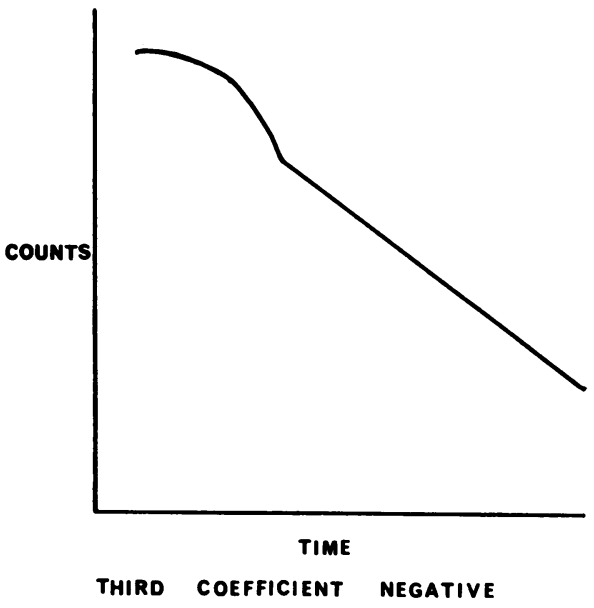

(b)

Fig. 3 Pattern of gastric emptying shown by the third coefficient of component analysis revealing changes in the early part of the emptying curve.
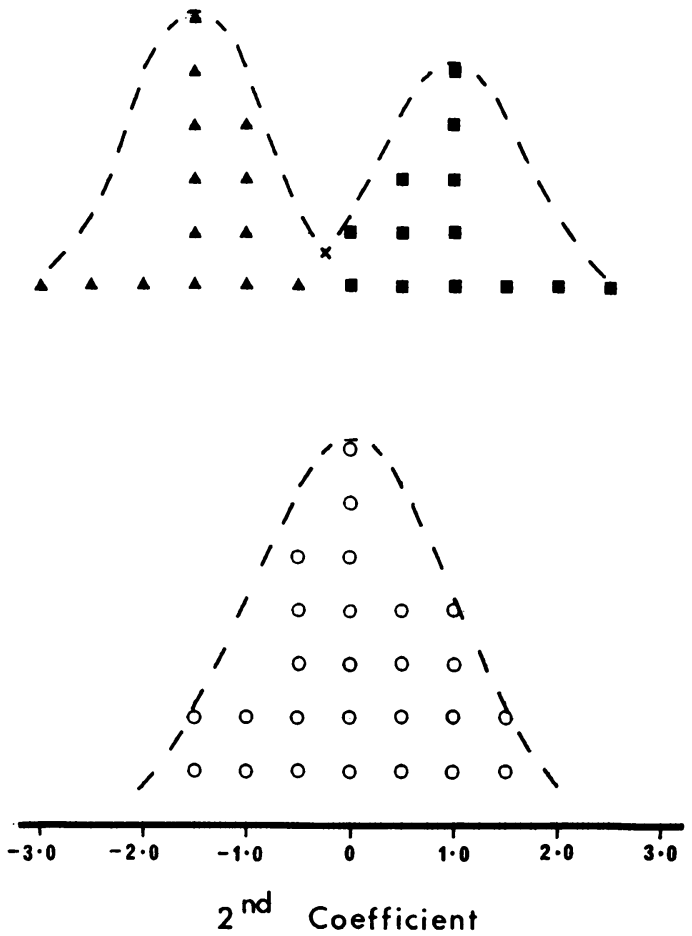

Fig. 4 Distribution of second coefficient of principal component analysis. $\mathrm{O}=$ Normal subjects. $\Delta=$ Duodenal ulcer patients (a subgroup). $\square=$ Duodenal ulcer patients ( $\beta$ subgroup). - - = Envelope of distributions (illustrative only). denal ulcer patients were divided into two groups, $\alpha$-with negative second coefficients, and $\beta$-with positive coefficients. The means of these two groups were significantly different from the mean of the control group $(P<0.01)$. The mean curves of the groups demonstrated clearly different patterns with a downward concavity in the $\alpha$ DU and a more linear shape in $\beta$ DU and control subjects (Fig. 5). The arbitrary subdivision of the DU group on the basis of the second coefficient may have introduced statistical bias. However, the distribution of the third coefficient also showed $\alpha$ DU to have a significantly different distribution from $\beta$ DU and normals.

The second coefficient of gastric emptying bore a significant $(P<0.05)$ correlation with peak gastric acidity ( $\mathrm{mEq} \mathrm{H}+/ 1)$ in the 15 patients who had secretory studies (Fig. 6).

Half emptying time No significant difference was found in distribution or in mean values between groups using the half emptying time.

Early emptying ratio The ratios in the groups showed no evidence of a fast initial phase, confirming the visual impression from the gamma camera screen. In fact, a slower initial emptying phase (indicated by a ratio greater than unity) was found in 18 of 26 normal subjects and 17 of 27 duodenal ulcer patients, the overall mean being significantly greater than $1.0(\mathrm{P}<0.02)$. 

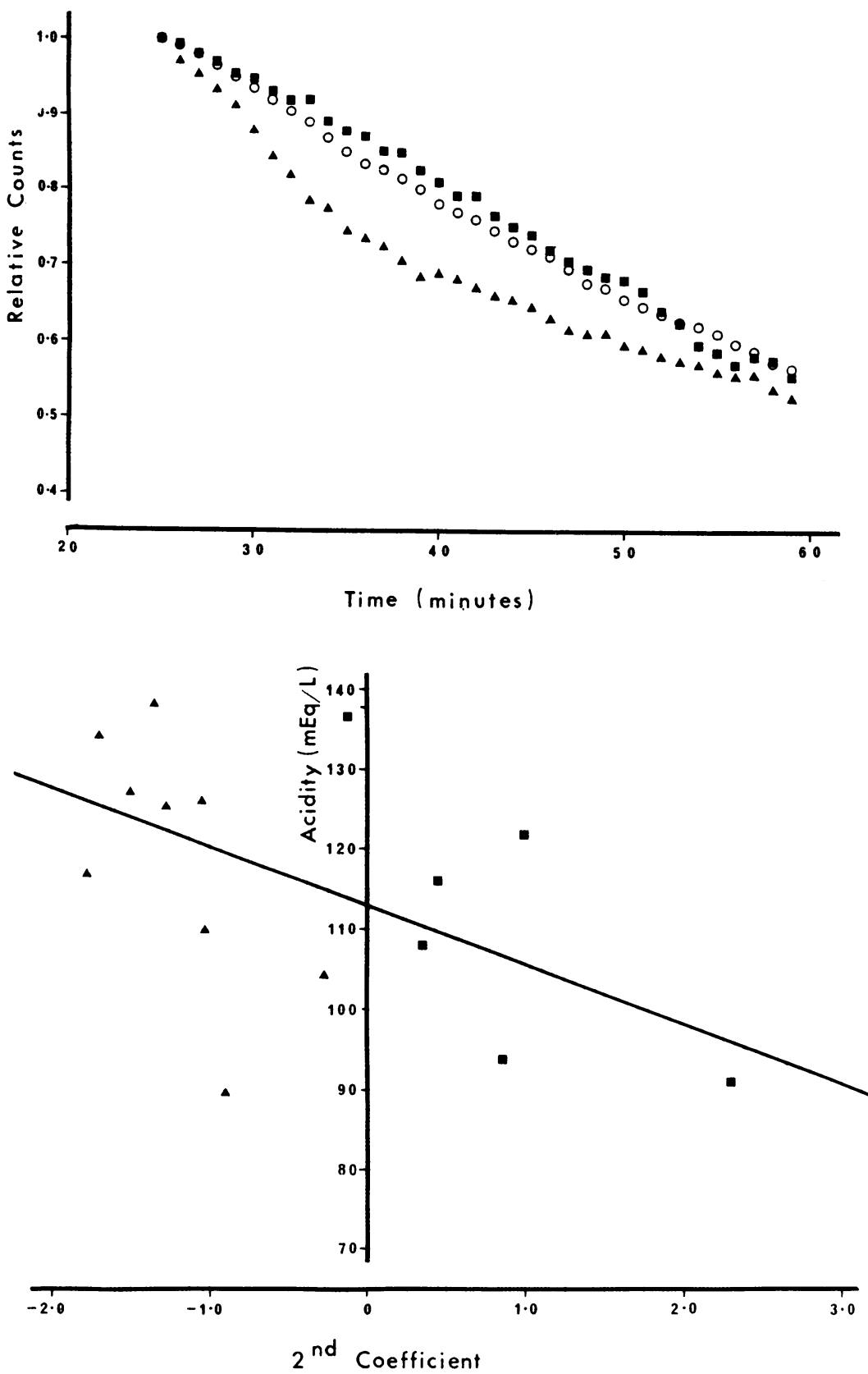

Fig. 5 Mean curves: relative counts (expressed as a ratio of mean count) plotted against time after starting to eat (minutes). $\bigcirc=$ Normal group. $\Delta=a$ duodenal ulcer subgroup. $\square=\beta$ duodenal ulcer subgroup.
Fig. 6. Correlation of acidity $(m E q / l)$ and second coefficient of principal component analysis. $\mathbf{\Delta}=$ a duodenal ulcer patients. $\square=\beta$ duodenal ulcer patients. $-=R e-$ gression line. Acidity $=$ $113.05-7.40 \times$ coefficient 2 . Correlation coefficient $0 \cdot 54$, significant at $5 \%$ level.

\section{AFTER VAGOTOMY}

Principal component analysis The first component showed a significant delay $(P<0.001)$ in gastric emptying one week after both types of vagotomy but no difference between the operations. At one month patients after TV were significantly slower $(\mathrm{P}<0.05)$ than preoperative or control subjects, whereas patients after HSV were not. By six months no significant differences were observed.

In the 14 patients who had four completed sequential studies the results obtained were identical with those of the larger groups. If, however, each postoperative result was then expressed in terms of the difference from that same patient's preoperative 


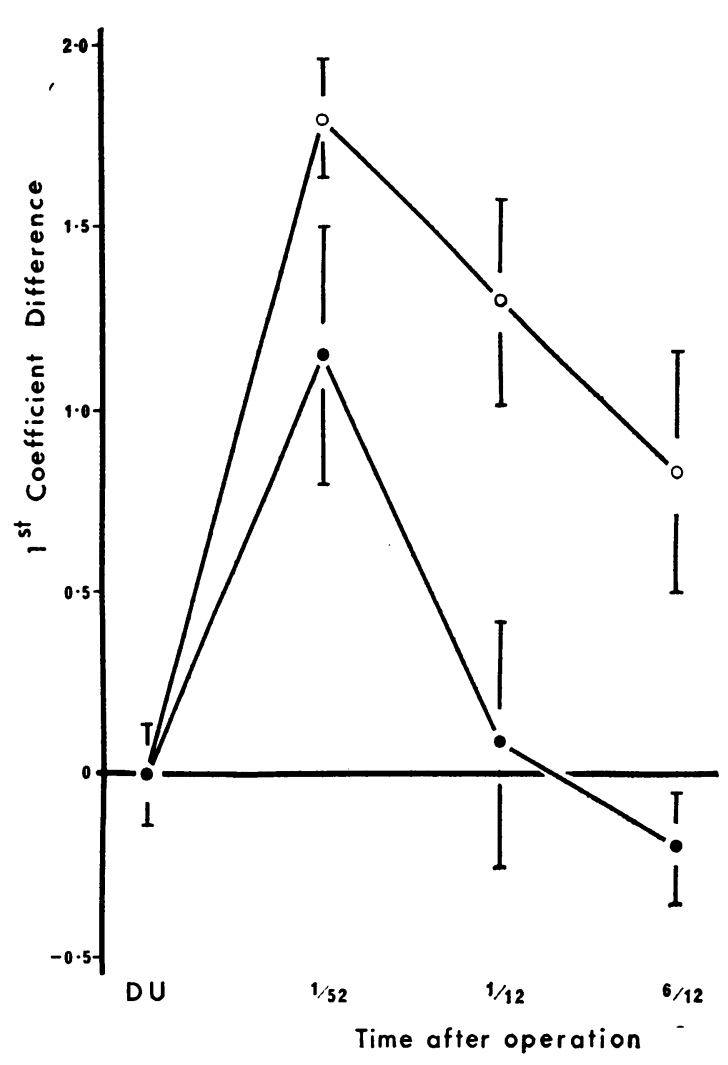

Fig. 7 Mean change in first coefficient relative to preoperative level plotted against time after operation. $=H S V$ group. $\bigcirc=T V+P$ group. $I= \pm 1$ standard error of mean.

result it was demonstrable that the TV group failed to return to preoperative levels at one month and six months $(P<0.04)$ (Fig. 7). There were no significant differences either between these groups before operation or between preoperative results and those of the control group.

The second and third components showed no difference between the groups when the initial data point was 25 minutes. However, in a subgroup of 11 patients with early data available within 15 minutes of beginning to eat the meal, possible correlation was found between rate of emptying in the early phase, indicated by the third coefficient, and a combined score for diarrhoea and dumping. As these differences were obtained only when the early data were analysed this part of the curve was examined for all the records using the early emptying ratio (see below). If all 24 records of patients at six months for whom there were clinical data were analysed from the later time of 25 minutes from beginning to eat, none of the symptoms showed a characteristic pattern with any of the analyses. No correlation was found between postoperative results and the respective preoperative subgroups ( $\alpha$ or $\beta$ DU), suggesting that the effects of the operation dominated the pattern of emptying.

Half emptying time The results were identical with those found for the first component. Median $\mathrm{T}_{\frac{1}{2}}$ values for the various groups are indicated in Table 2. (Medians were used, as the distributions were skewed by some extremely long $T_{\frac{1}{2}}$ results after operation.)

Early emptying ratio The preoperative group and the HSV group at six months both had an initial phase of gastric emptying which appeared slower than the subsequent emptying rate in each group (Table 3). Patients at six months after TV did not exhibit this slower phase, the difference between operations being significant $(\mathrm{P}<0.05)$.

Correlation with symptoms In this small group of 24 patients studied prospectively, only minor and mild symptoms were noted. None had severe symptoms. A significantly greater incidence of episodic diarrhoea was found after TV (six patients) than after HSV (one patient) $(\mathrm{P}<0.05)$. A combined score for diarrhoea and dumping showed a significant difference $(\mathrm{P}<0.05)$ between the TV and HSV

Table 2 Half emptying time

\begin{tabular}{lc}
\hline Group & $\begin{array}{l}\text { Median half emptying time } \\
\pm S E \text { of median (min) }\end{array}$ \\
\hline Control & $44 \pm 7$ \\
DU & $40 \pm 4$ \\
At one week & $148 \pm 25$ \\
HSV & $130 \pm 25$ \\
TV & $53 \pm 12$ \\
At one month & $83 \pm 18$ \\
HSV & $51 \pm 12$ \\
TV & $49 \pm 10$ \\
At six months & \\
HSV &
\end{tabular}

HSV: Highly selective vagotomy.

TV: Truncal vagotomy and pyloroplasty.

Table 3 Early emptying ratio*

\begin{tabular}{lll}
\hline Group & Mean $\pm S E$ of mean & Difference from unity \\
\hline Control and DU & $1.049 \pm 0.019$ & $\mathrm{P}<0.02$ \\
At six months & $1.050 \pm 0.017$ & $\mathrm{P}<0.02$ \\
HSV & $0.985 \pm 0.035$ & NS \\
TV &
\end{tabular}

*A ratio of unity indicates even emptying, greater than unity slower in the early phase, and less than unity faster in the early phase. 
groups with the majority of HSV patients being symptom-free.

1. Principal component analysis The third coefficient which describes the early phase of gastric emptying was found to distinguish two patients with moderate diarrhoea in the subgroup of 12 in whom we were able to begin recording within five minutes of eating the meal. These two patients had the most positive coefficient indicating a rapid instead of a slower initial emptying. If all 24 records were analysed commencing from the later time of 25 minutes from beginning to eat, there was no separation of patients with diarrhoea. Neither dumping nor any of the other symptoms showed a characteristic pattern with any of the analyses.

2. Half emptying time ( $\left(T_{\frac{1}{2}}\right)$ No correlation could be found in the 24 patients between $T \frac{1}{2}$ and either the overall symptom score or any of the individual symptoms, in particular dumping or diarrhoea.

3. Initial emptying phase In 20 patients, enough early data were present to permit calculation of the ratio. The patients after truncal vagotomy and pyloroplasty (TV) had a significant correlation $(r=$ 0.87 ) between the initial emptying ratio and the combined score for dumping and diarrhoea. Patients after highly selective vagotomy (HSV) did not show any such correlation (Fig. 8). However, further

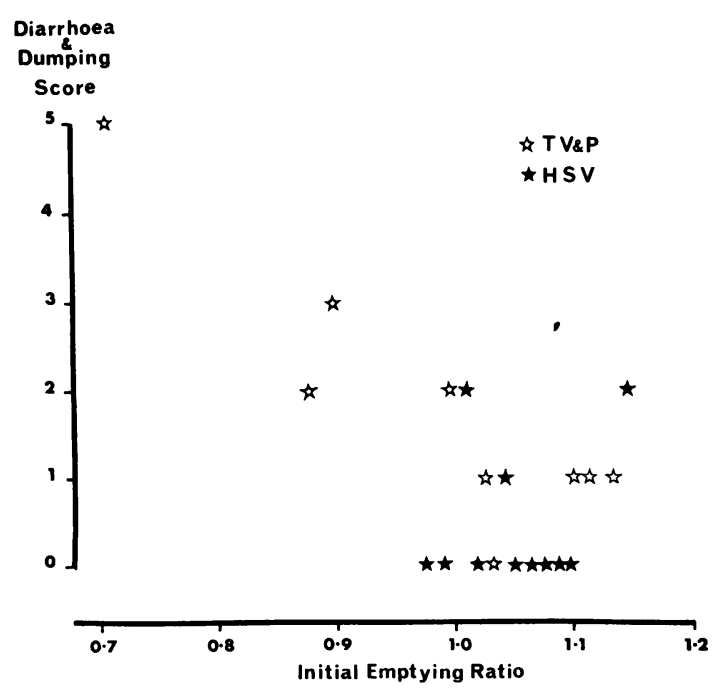

Fig. 8 Relationship between combined symptom score for diarrhoea and dumping and the initial emptying ratio after vagotomy. analysis of these ratios showed that this was a fortuitous correlation because moving the reference point for calculating the ratio by two minutes gave a correlation of about 0.5 which was not significant.

\section{Discussion}

While the overall emptying rate of the stomach can be assessed by the half emptying time (T $\left.\frac{1}{2}\right)$ its usefulness as a measure of the pattern of emptying has been brought into question by our results. The closeness of fit of an exponential to the original data has often been expressed in terms of correlation coefficient, which merely demonstrated that the stomach empties with time. Frequently the data points were not randomly distributed around the exponential curve and further inaccuracies arose from extrapolation of the curve beyond the data points.

We have found the method of principal component analysis useful because it does not require any preconceived concepts about the functional form of the data. For example, the exponential model did not detect two subgroups of duodenal ulcer patients which were separated using principal component analysis. The patterns must still be explained in physiological terms but the features identified by principal components can be further assessed by simpler analytical methods such as the early emptying ratio. The main disadvantage of principal component analysis is conceptual. When it is compared with the half emptying time, it presents an aura of mystery to the non-mathematical clinician who may feel some doubt as to whether anything revealed by such manipulation can have a physiological significance. It is also not transferable from one series of tests to another unless the parameters of the study are the same.

Previous comparisons of gastric emptying rates in patients with duodenal ulcers compared with normal subjects have not shown a uniform pattern. Using liquid meals no difference in the rate of gastric emptying has been established (George, 1968; Cobb et al., 1971). Using a solid meal of food and barium and measuring total emptying time Buckler (1967) was also unable to identify a different rate in duodenal ulcer patients. Two other groups using solid meals showed faster gastric emptying in duodenal ulcer patients (Griffith et al., 1968; Fordtran and Walsh, 1973). Our study failed to separate the duodenal ulcer and control patients when using $\mathrm{T}_{\frac{1}{2}}$ but did show the patterns to be different using component analysis, suggesting a difference within the duodenal ulcer group.

The relationship of the second coefficient of component analysis of gastric emptying to peak 
acidity is difficult to explain in functional terms. It is possible that the concavity in the emptying curve of $\alpha$ DU patients indicated by a negative second coefficient may be due to the higher peak acidity activating duodenal inhibitory mechanisms to give a relative slowing in the later part of the gastric emptying. An alternative explanation for this concavity may be that, after an initial faster phase, the apparent slowing is due to the small volume of meal remaining in the stomach. This finds support from a later apparent slowing in records extending beyond 60 minutes in control and $\beta$ subjects. In addition, it might explain the difference between our results and the studies showing faster emptying in DU subjects (Griffith et al., 1968; Fordtran and Walsh, 1973) when meals of $550 \mathrm{ml}$ (twice the volume of our meal) were given. An apparent slowing due to a small residual volume would occur at a later stage in these other studies.

The findings of a delay in gastric emptying soon after vagotomy and pyloroplasty which later reverted to normal (Cowley et al., 1972) has been confirmed in this study. A similar temporary disruption in the rate of gastric emptying was detected after HSV in dogs (Wilbur and Kelly, 1973), and this effect was found to persist for many months after operation in man (Humphrey and Wilkinson, 1972; Clarke and Alexander-Williams, 1973). The apparent discrepancies with other results can be explained by the type of meal chosen. The increased rate of emptying seen with liquid meals was due, presumably, to the loss of receptive relaxation of the stomach found after vagotomy (Koster and Madsen, 1970; Staadas and Aune, 1970; Wilbur and Kelly, 1973). The solid meal used in the present study may have required a greater motor activity to grind and emulsify the food as well as to push it into the duodenum (Carlson $e t$ al., 1966). This ability was temporarily lost by a combination of gastric dissection and partial denervation. The temporary delay in gastric emptying after HSV did not cause concern clinically since it passed off without the need for a drainage procedure.

While within one month of surgery there was considerable improvement after both types of operation, TV patients emptied significantly more slowly than normal (first coefficient and $\mathrm{T} \frac{1}{2}$ ), whereas HSV did not. The pattern of emptying at six months was also altered after TV in some patients. Some supportive data were obtained by the loss of the slower initial emptying phase in a proportion of TV patients. In brief, although many comparisons have been made using three methods of analysis, by six months from the operation HSV patients have not been shown to have a significant difference from normal, whereas some of the TV patients still exhibit abnormalities of gastric emptying although the group as a whole tends to return to normal.

Attempts to explain the changes in gastric emptying after vagotomy are largely speculative. At one week after operation the gross delay after both operations was not surprising in the case of TV when all the gastric masculature has been vagally denervated and direct measurements of motility and of myoelectrical activity show disruption of the normal pattern (Stoddard et al., 1973). After HSV the antrum remained innervated but at this early stage was not so mechanically active as normal. In the longer term after TV the only change noted was the lack of the slower initial phase of emptying. This may have been due to the disorganisation of the antropyloric mechanism by the pyloroplasty which allows food to escape before it is fully mixed and churned by the antral contractions-a mechanism preserved in highly selective vagotomy when no pyloroplasty is used.

The restricted correlation between symptoms and gastric emptying may reflect our choice of a solid test meal. It has been shown that whereas emptying patterns with a fluid meal correlate with dumping symptoms, those after a solid meal do not (Alexander-Williams et al., 1973). We have been able to extend these findings but only with the special analysis of the early phase of emptying. Most provocative tests for symptoms utilise a hypertonic fluid meal and none of our patients experienced dumping or diarrhoea after eating our solid meal. A larger series is needed to expand the results in the early phase when a solid meal may be a suitable index of the likelihood of diarrhoea. On the other hand, it may be that the fluid component of meals is the main factor provoking dumping or diarrhoea.

Care has also to be taken in the highly subjective matter of assessing symptoms after operation. We used a separate observer who has concentrated on this topic and who was unaware of the results of the gastric emptying tests. Despite these precautions, it has to be noted that assessment of whether a symptom is present or not is more reliable than an estimate of its severity (DeDombal et al., 1974). Numbers are too small to permit comparisons of the symptomatic results of the two procedures but the overall symptom score was the same for both.

Is the extra analysis of the emptying curves worth the trouble? We have found it helpful in establishing numerical values for changes in shape of emptying curves in the identification of subgroups in duodenal ulcer patients and in the attention drawn to the early phase of emptying, characterised by the third coefficient, when attempting to correlate symptoms with gastric emptying patterns. However, the clinical significance of these changes has still to be established by additional prospective studies. 


\section{References}

Alexander-Williams, J., Donovan, I. A., Gunn, I. F., Brown, A., and Harding, L. K. (1973). The effect of vagotomy on gastric emptying. Proceedings of the Royal Society of Medicine, 66, 1102-1103.

Amdrup, E., Jensen, H. E., Johnston, D., Walker, B. E., and Goligher, J. C. (1974). Clinical results of parietal cell vagotomy (highly selective vagotomy) two to four years after operation. Annals of Surgery, 180, 279-284.

Barber, D. C., Duthie, H. L., Howlett, P. J., and Ward, A. S. (1974). Principal components: a new approach to the analysis of gastric emptying. Proceedings of Symposium on Dynamic Studies with Radioisotopes in Medicine. Knoxville, Ga. International Atomic Energy Agency, IAEA/STI/PUB/376. Vienna.

Buckler, K. G. (1967). Effects of gastric surgery upon gastric emptying in cases of peptic ulceration. Gut, 8, 137-147.

Carlson, H. C., Code, C. F., and Nelson, R. A. (1966). Motor action of canine gastroduodenal junction: a cineradiographic, pressure, and electrical study. American Journal of Digestive Diseases, 11, 155-172.

Clarke, R. J., and Alexander-Williams, J. (1973). The effect of preserving antral innervation and of a pyloroplasty on gastric emptying after vagotomy in man. Gut, 14, 300-307.

Cobb, J. S., Bank, S., Marks, I. N., and Louw, J. H. (1971). Gastric emptying after vagotomy and pyloroplasty. Relation to some postoperative sequelae. American Journal of Digestive Diseases, 16, 207-215.

Cowley, D. J., Vernon, P., Jones, T., Glass, H. I., and Cox, A. G. (1972). Gastric emptying of solid meals after truncal vagotomy and pyloroplasty in human subjects. Gut, 13, 176-181.

DeDombal, F. T., Horrocks, J. C., and Clamp, S. E. (1974). Observer variation in the assessment of results of surgery for peptic ulceration. Gut, 15, 824. (Abstract.)

Fordtran, J. S., and Walsh, J. H. (1973). Gastric acid secretion rate and buffer content of the stomach after eating: results in normal subjects and in patients with duodenal ulcer. Journal of Clinical Investigation, 52, 645-657.

George, J. D. (1968). Gastric acidity and motility. American Journal of Digestive Diseases, 13, 376-383.

Griffith, G. H., Owen, G. M., Campbell, H., and Shields, R. (1968). Gastric emptying in health and in gastroduodenal disease. Gastroenterology, 54, 1-7.

Howlett, P. J., Ward, A. S., and Duthie, H. L. (1974). Gastric emptying after vagotomy. Proceedings of the Royal Society of Medicine, 67, 836-838.
Humphrey, C. S., Johnston, D., Walker, B. E., Pulvertaft, C. N., and Goligher, J. C. (1972). Incidence of dumping after truncal and selective vagotomy with pyloroplasty and highly selective vagotomy without drainage procedure. British Medical Journal, 3, 785-788.

Humphrey, C. S., and Wilkinson, A. R. (1972). The value of preserving the pylorus in the surgery of duodenal ulcer. British Journal of Surgery, 59, 779-783.

Johnston, D., and Wilkinson, A. R. (1970). Highly selective vagotomy without a drainage procedure in the treatment of duodenal ulcer. British Journal of Surgery, 57, 289-296.

Kelly, J. M., and Kennedy, T. L. (1971). Does highly selective vagotomy preserve antral motility. Gut, 12, 866 (Abstract).

Koster, N., and Madsen, P. (1970). The intragastric pressure before and immediately after truncal vagotomy. Scandinavian Journal of Gastroenterology, 5, 381-383.

McKelvey, S. T. D. (1970). Gastric incontinence and postvagotomy diarrhoea. British Journal of Surgery, 57, 741-747.

Madsen, P., Kronborg, O., and Feldt-Rasmussen, K. (1973). The gastric emptying and small intestinal transit after highly selective vagotomy without drainage and selective vagotomy with pyloroplasty. Scandinavian Journal of Gastroenterologv, 8, 541-543.

Moberg, S., Cariberger, G., Barany, F., and Lundh, G. (1972). Gastric emptying in peptic ulcer patients before and after partial gastrectomy and selective proximal vagotomy. Rendic. Gastroenterol., 4, 1-7.

Pederson, G., and Amdrup, E. (1970). The gastro-intestinal passage of a physiological contrast medium in duodenal ulcer patients before and after vagotomy of the parietal cell mass with preserved antral innervation or a selective gastric vagotomy with a Finney pyloroplasty. Fourth World Congress of Gastroenterology, Advance Abstracts., pp. 433. Edited by P. Riis, P. Anthonisen, and H. Baden. Danish Gastroenterological Association: Copenhagen.

Staadas, J., and Aune, S. (1970). Intragastric pressure/volume relationship before and after vagotomy. Acta Chirurgica Scandinavica, 136, 611-615.

Stoddard, C. J., Waterfall, W. E., Brown, B. H., and Duthie, H. L. (1973). The effects of varying the extent of the vagotomy on the myoelectrical and motor activity of the stomach. Gut, 14, 657-664.

Wilbur, B. G., and Kelly, K. A. (1973). Effect of proximal gastric, complete gastric and truncal vagotomy on canine gastric electric activity, motility and emptying. Annals of Surgerv, 178, 295-303. 